\title{
Sermão do Dia de Cinza, do padre Antônio de Sá (Rio de Janeiro, 1620-1678): um caso de estrutura correlativa
}

Gilson J. Santos Universidade Federal de Minas Gerais

\section{Introdução}

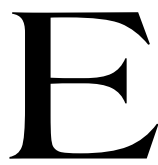

ntre os textos do período colonial brasileiro que precisam, inadiavelmente, de edições fiáveis, estão os de Antônio de Sá (Rio de Janeiro, 1620-1678). O orador, que viveu quase toda a vida no Brasil, fez aqui seus estudos, ordenou-se e pregou o Evangelho.

O Sermão do Dia de Cinza é o texto mais comentado e elogiado do orador jesuíta. O texto tem quatro ediçóes conhecidas: a primeira é de 1669; a segunda, de 1673; a terceira está incluída na edição dos Sermões Vários (volume que reúne, pela primeira e única vez, os dezessete sermões do padre), publicados em 1750; e a quarta, no volume Antônio de Sá, da Estante Clássica da Revista de Língua Portuguesa, de 1924. Em 2006, o sermão foi reeditado, como parte de uma dissertação de mestrado ${ }^{1}$ defendida na Faculdade de Letras da UFMG. O texto do sermão, nessa reedição, é a base deste estudo.

No sermão, pregado na Capela Real, em Lisboa, ${ }^{2}$ por ocasião da Quaresma, Antônio de Sá procura persuadir o monarca português e a sua

\footnotetext{
${ }^{1}$ SANTOS, 2006, p. 27-99.

${ }^{2}$ A data da pregação do sermão é incerta. Notícias biográficas fornecidas por Serafim Leite (História da Companhia de Jesus no Brasil, t. IX, 1950, p. 106-107.) sugerem que a pregação ocorreu em algum momento entre 1662 e 1665.
} 
corte ao temor de Deus e à piedade. A questão fundamental que norteia toda a sua argumentação é a mortalidade do homem, sobretudo do homem nobre.

Nesta análise, privilegiamos o levantamento analítico de elementos internos do sermão, sobretudo os ligados à disposição de paradigmas gramaticais, ao longo do texto; isto é: procuramos mostrar a lógica que ordena esses termos no texto. O propósito fundamental é descrever, no sermão, as correlações especiais de determinados termos-chave, que são responsáveis pela estrutura arborescente e decorativa do discurso - o seu princípio básico ordenador.

É preciso advertir o leitor de que, para entendermos a correlação na prosa, servimo-nos dos pressupostos teóricos - relativos à correlação poética na poesia barroca - apresentados por Dámaso Alonso no ensaio "Táticas dos conjuntos semelhantes na expressão literária”. ${ }^{3}$ Nesse ensaio, Dámaso Alonso adverte, ainda, que, apesar de operar com exemplos poéticos, tudo o que diz tem aplicação imediata à prosa. ${ }^{4}$

\section{Epígrafes e Partição}

O discurso religioso português seiscentista apresenta, normalmente, uma citação latina, em forma de epígrafe, retirada das Sagradas Escrituras, cuja função é fornecer o tema (conceito predicável) e direcionar a argumentação a ser desenvolvida no sermão. Nesse sermão, Antônio de Sá empregou três epígrafes - o que é, certamente, um artifício engenhoso e raro, ${ }^{5}$ porventura uma inovação retórica, se considerarmos que desempenham funções distintas.

As três citações constituem atos perlocutórios divinos; ou seja, são enunciados que exercem efeito sobre o ouvinte - amedrontar, persuadir,

${ }^{3}$ ALONSO, 2002, p. 317-340.

${ }^{4}$ ALONSO, 2002, p. 336.

${ }^{5}$ Não encontramos, nos sermões de Antônio Vieira, artifício dessa natureza. 
etc. -, dependendo, por isso, fundamentalmente, da situação da enunciação: na primeira, Deus exorta-nos ao arrependimento, por meio de palavras do profeta Joel - "Convertimini ad me in toto corde vestro"; ${ }^{6}$ na segunda, Cristo aconselha-nos ao desapego dos bens terrenos - "Nolite thesaurizare vobis tesauros in terra"; $;$ e, na terceira, a Igreja alerta-nos ${ }^{8}$ sobre nossa mortalidade, retomando uma declaração de Deus feita por ocasião da expulsão de Adão e Eva do Paraíso - "Memento homo, quia pulvis es, et in pulverem reverteris".

Apenas uma das citaçóes latinas desempenha o papel de conceito predicável, a terceira delas; as outras duas a confirmam nessa função. $\mathrm{O}$ pregador evangélico elegeu por tema predicável o ameaçador aviso da Igreja - "Memento homo, quia pulvis es, et in pulverem reverteris." O pregador dividiu esse aviso em duas seçôes e as vinculou às duas epígrafes de apoio. A primeira seção, que apresenta o ouvinte no tempo presente - "Memento homo, quia pulvis es" -, desencadeia a primeira parte da argumentação, nisso sendo abonada pelas palavras de Cristo, da segunda epígrafe - "Nolite thesaurizare vobis tesauros in terra". A segunda seção do conceito predicável, que situa o ouvinte no tempo futuro - "et pulverem reverteris" -, alimenta a segunda parte da argumentação, sendo afiançada pelo chamamento de Deus, presente na primeira das epígrafes - "Convertimini ad me in toto corde vestro". Com essa disposição dos temas latinos, o jesuíta indica que suas palavras se fundam na verdade, pois são palavras da Igreja fundadas em palavras de Cristo e de Deus.

${ }^{6}$ Jl 2, 12 ["Agora, portanto - oráculo de Iahweh - retornai a mim de todo vosso coração, com jejum, com lágrimas e gritos de luto."]

${ }^{7}$ Mt 6, 19 ["Não ajunteis para vós tesouros na terra, onde a traça e o caruncho os corroem e onde os ladróes arrombam e roubam".]

8 As palavras "Memento homo" (= "Lembra-te, homem") são palavras com que a igreja exorta os cristãos a se lembrarem das palavras ditas por Deus a Adão, por ocasiāo de sua expulsão do paraiso.

${ }^{9}$ Gn 3, 19 ["Com o suor de teu rosto comerás teu pão até que retornes ao solo, pois dele foste tirado. Pois tu és pó e ao pó tornarás.”] 
A divisão do tema em duas partes ou metades já aparece, em termos gerais, embora ainda como unidade, no primeiro parágrafo do sermão. Mas é no parágrafo 2 que a citação latina se apresenta dividida. A construção da partição associa as duas metades do conceito às duas epígrafes, segunda e primeira, respectivamente, por meio de paralelismo binário. A divisão binária prenuncia os dois momentos da argumentação, indicando a função organizadora que essa partição exerce no discurso: "Homem, pelo que és [pó], lembra-te de ouvir a Cristo, e aborrecer ao mundo: Nolite thesaurizare vobis tesauros in terra; homem, [pelo] que hás de ser [pó], lembra-te de ouvir a Deus e reduzir-te a sua graça: Convertimini ad me."10

\section{Ordenação Correlativa e Desenvolvimento da Argumentação}

A organização da matéria no sermão obedece aos preceitos da eloqüência clássica. As divisões são bem marcadas: o exórdio ocupa os parágrafos 1 e 2 . O desenvolvimento da argumentação estende-se do parágrafo 3 ao 37 e pode ser dividido em duas partes complementares: a primeira parte é formada pelos parágrafos 3 ao 26 - ela admite, por sua vez, uma subdivisão interna, cujo marco é o parágrafo 9-; a segunda parte vai do parágrafo 27 ao 37 . A peroração ocupa o parágrafo final, 38.

O primeiro aspecto notável desse sermão é a ordenação correlativa de suas partes. Se considerarmos os conceitos disseminados no texto, entre os parágrafos 10 e 24 - que aparecem nesta ordem: "grandezas de maior nome”, "glórias”, "honras”, "privança”, "despachos”, "postos”, "aplausos”, "prosperidade", "fermosura”, "amor”, "gostos”, "deleites”, "riquezas”, "amizades" e "corte" -, notaremos que todos os elementos dessa série derivam de um termo comum, geral e mais abstrato, e que todos eles são recoletados, um a um, nos parágrafos 25 e 38, na mesma ordem em que estão disseminados. Exceção feita ao termo "glória", que, por uma razão especial, teve seu lugar natural alterado no parágrafo 38.

${ }^{10}$ SÁ, 2006, p. 31. 
A palavra essencial,

[...] aquela que reunir a idéia comum a todas as outras, que puder substituir-se a todas elas sem grande prejuízo de significação, é chamada em estilística o termo identificador. A este termo fundamental, que traduz a idéia pura, condensada, se referem todos os outros. ${ }^{11}$

A idéia fundamental da série foi apresentada já no parágrafo 1 ("bens da terra") e repetida, ao longo do texto, sob determinadas formas variantes: "cousas da terra", "cousas do mundo", "prendas do mundo" e "tesouros da terra". Os "bens da terra" são os bens materiais e humanos, com o sentido que têm nas escrituras canônicas.

Segundo Dámaso Alonso, a "Retórica, desde a Idade Média, descobriu e descreveu a seu modo um artificiosíssimo procedimento de ordenação, de cujos nomes o mais generalizado foi o de 'correlação poética"'. ${ }^{12}$ Mas o próprio Dámaso Alonso, no mesmo ensaio citado, observa: "Todo o tempo operamos com exemplos poéticos: mas tudo que se disse tem aplicação imediata à prosa; aí está, se faltam exemplos próximos, a prosa dos séculos XVI e XVII.". ${ }^{13}$ No Sermão do Dia de Cinza, o sistema das ordenaçôes equivale ao das "correlaçôes" que o crítico literário detectou e descreveu na poesia de Gôngora.

Margarida Vieira Mendes retomou o conceito de "correlação poética" em sua obra A oratória barroca de Vieira, tal como formulado por Dámaso Alonso no estudo que nos serviu de base teórica. A autora, além de apontar a ocorrência de correlações na prosa barroca ibérica seiscentista, exemplificando com trechos de sermões de Vieira, cita teóricos que, sem usar o termo "correlação poética", desenvolveram estudos relativos a esse aspecto comum à poesia e à prosa barrocas. ${ }^{14}$

${ }^{11}$ LAPA, 1973, p. 27.

${ }^{12}$ ALONSO, 2002, p. 319-320.

${ }_{13}^{13}$ ALONSO, 2002, p. 336.

${ }^{14}$ MENDES, 1984, p. 463. 
A correlação é um encadeamento de conjuntos semelhantes, ligados a um conceito plurissignificativo ou imagem capaz de ordená-los em conjuntos semelhantes. Por exemplo:

$\$ 17$ Que é a prosperidade $\left[\mathrm{A}_{8}\right]$ senão um temporal à popa $\left[\mathrm{B}_{8}\right]$

$\$ 18$ Que é a fermosura $\left[A_{9}\right]$ senão uma caveira bem encarnada $\left[B_{9}\right]$

constituem três conjuntos semelhantes entre si, porque pertencem todos a um mesmo campo conceitual: o dos "bens da terra".

$\mathrm{Na}$ amostra acima, ainda fragmentária, ou seja, parcial, apenas para a exemplificação inicial da idéia de "conjunto", podemos dizer que $\mathrm{A}_{8} \mathrm{e} \mathrm{A}_{9}$ são semelhantes entre si, porque representam variaçóes particularizadas do conceito fundamental "bens da terra"; $\mathrm{B}_{8}$ e $\mathrm{B}_{9}$, por seu turno, são semelhantes enquanto espécies antitéticas e integrantes, por um sistema de algum modo oposto ao primeiro conjunto, de $\mathrm{A}_{8}$ e $\mathrm{A}_{9}$, respectivamente. Assim, as díades "prosperidade" (= "temporal à popa") e "fermosura" (= "caveira bem encarnada") formam dois conjuntos binários, análogos e opostos, termo a termo: $\mathrm{A}_{8}, \mathrm{~B}_{8}$ e $\mathrm{A}_{9}, \mathrm{~B}_{9}$. A soma de todas as dualidades (entre os parágrafos 10 e 24) compõe o termo identificador, que representamos, simplesmente, por "AB".

Vejamos, de uma só vez, o esquema geral do texto:

$\$ 1$ bens da terra $[\mathrm{AB}]$

$\$ 3$ cousas da terra $[A B]$

$\$ 9$ cousas do mundo $[\mathrm{AB}]$

$\$ 10$ Que são as grandezas de maior nome $\left[\mathrm{A}_{1}\right]$ senão grandezas de nome $\left[\mathrm{B}_{1}\right]$

$\$ 11$ Que é a glória $\left[A_{2}\right]$ senão um deixar de ser $\left[\mathrm{B}_{2}\right]$

$\S 12$ Que são as honras $\left[\mathrm{A}_{3}\right]$ senão aparatosas tramóias da fortuna $\left[\mathrm{B}_{3}\right]$

$\$ 13$ Que é a privança $\left[\mathrm{A}_{4}\right]$ senão luz de Estrela $\left[\mathrm{B}_{4}\right]$

$\$ 14$ Que são os despachos $\left[\mathrm{A}_{5}\right]$ senão um sim de patrocinados e um não de beneméritos $\left[B_{5}\right]$ 


\section{$\$ 15$ Que são os postos [A $]$} senão subidas cujos degraus se vencem a quedas $\left[\mathrm{B}_{6}\right]$

$\$ 16$ Que são os aplausos da fama $\left[\mathrm{A}_{7}\right]$ senão reclamo de ódios $\left[\mathrm{B}_{7}\right]$

$\$ 17$ Que é a prosperidade $\left[\mathrm{A}_{8}\right]$ senão um temporal à popa $\left[\mathrm{B}_{8}\right]$

$\$ 18$ Que é a fermosura $\left[\mathrm{A}_{9}\right]$ senão uma caveira bem encarnada $\left[\mathrm{B}_{9}\right]$

$\$ 19$ Que é o amor $\left[A_{10}\right]$ senão um inferno com fogo sem eternidade $\left[B_{10}\right]$

$\$ 20$ Que são os gostos $\left[A_{11}\right]$ senão ciladas dos pesares $\left[\mathrm{B}_{11}\right]$

$\$ 21$ Que são os deleites $\left[A_{12}\right]$ senão remansos enlodados $\left[\mathrm{B}_{12}\right]$

$\$ 22$ Que são as riquezas $\left[A_{13}\right]$ senão marés do oceano $\left[\mathrm{B}_{13}\right]$

$\$ 23$ Que são as amizades $\left[\mathrm{A}_{14}\right]$ senão lisonjas da erva do sol $\left[\mathrm{B}_{14}\right]$

$\$ 24$ Que é finalmente a corte $\left[A_{15}\right]$ senão uma roda arrebatada $\left[\mathrm{B}_{15}\right]$

$\$ 25$ Eis aqui o mundo $[\mathrm{AB}]$, eis aqui as melhores prendas do mundo $[A B]:(\ldots)$ que se desvele o soberbo por tais grandezas $\left[A_{1}\right]$, o desvanecido por tal glória $\left[A_{2}\right]$, o ambicioso por tais honras $\left[A_{3}\right]$, o palaciano por tal privança $\left[A_{4}\right]$, o requerente por tais despachos $\left[A_{5}\right]$, o cortesão por tais postos $\left[\mathrm{A}_{6}\right]$, o presumido por tal fama $\left[\mathrm{A}_{7}\right]$, o invejoso por tal prosperidade $\left[A_{8}\right]$, o divertido por tal formosura $\left[A_{9}\right]$, o afeiçoado por tal amor $\left[A_{10}\right]$, o delicioso por tais gostos $\left[A_{11}\right]$, o lascivo por tais deleites $\left[A_{12}\right]$, o cobiçoso por tais riquezas $\left[A_{13}\right]$, e todos por tais amizades $\left[A_{14}\right]$, por tal corte $\left[A_{15}\right]$, e por tal mundo $[A B](\ldots)$ bens da terra $[A B]$.

$\$ 26$ tesouros da terra $[A B]$, bens da terra $[A B]$

$\$ 38$ Ora fiéis, conhecida a vileza do mundo $[\mathrm{AB}]$ à vista da baixeza de nosso ser: (...); E reconhecida a importância de nossa conversão à 
vista da fragilidade de nossas vidas; [...]: não permitamos que em tanto dano de nossas almas, se malogre o conselho de Cristo, e a vocação de Deus: (...) a Deus pois com os corações, ao Céu com ânsias, ali tendes grandezas $\left[A_{1}\right]$ sem vaidade $\left[B_{1}\right]$, honras $\left[A_{3}\right]$ sem baixos $\left[B_{3}\right]$, privança $\left[A_{4}\right]$ sem receio $\left[B_{4}\right]$, despachos $\left[A_{5}\right]$ sem dependência $\left[B_{5}\right]$, postos $\left[A_{6}\right]$ sem desdouro $\left[B_{6}\right]$, fama $\left[A_{7}\right]$ sem inveja $\left[B_{7}\right]$, prosperidade $\left[A_{8}\right]$ sem perigo $\left[B_{8}\right]$, fermosura $\left[A_{9}\right]$ sem eclipse, e sem mudança $\left[B_{9}\right]$, amor $\left[A_{10}\right]$ sem tormento, e sem ruína $\left[B_{10}\right]$, gostos $\left[A_{11}\right]$ sem pesar $\left[B_{11}\right]$, deleites $\left[A_{12}\right]$ sem sede $\left[B_{12}\right]$, riquezas $\left[A_{13}\right]$ sem limitação $\left[B_{13}\right]$, amizade $\left[A_{14}\right]$ sem lisonja $\left[B_{14}\right]$, Corte $\left[A_{15}\right]$ sem voltas $\left[B_{15}\right]$, e glória $\left[\mathrm{A}_{2}\right]$ sem fim $\left[\mathrm{B}_{2}\right]$.

Nos parágrafos 1, 3 e 9, é apresentado o termo identificador; nos parágrafos 10 a 24, disseminam-se as particularizaçóes do termo, que retorna no parágrafo 26. Antes, porém, da retomada do termo identificador, o parágrafo 25 realiza a recolha das particularizaçóes disseminadas nos parágrafos anteriores. Ao final do sermão, em seu último parágrafo, o de número 38, nova recolha-agora realizada de uma maneira diferente da anterior. Essa diferença específica do último parágrafo será analisada a seu tempo.

\section{Termo Identificador}

A primeira parte do desenvolvimento estende-se do parágrafo 3 ao 26, com uma subdivisão interna, da qual a passagem do parágrafo 9 ao 10 é o ponto-chave. No início da argumentação, logo no parágrafo 3, o orador trata da condição presente de seu ouvinte, lembrando-lhe "a desestima das cousas da terra" aconselhada por Cristo:

Atenta, pois, a Igreja a conseguir de nós a desestima das cousas da terra, que nos aconselha hoje a nossas vontades Cristo, nos traz à memória a terra de nosso ser, para que à vista do que somos [pó] possamos inferir o que é o mundo. ${ }^{15}$

${ }^{15}$ SÁ, 2006, p. 33. 
As “cousas da terra”, aí mencionadas, são uma retomada do termo identificador - "bens da terra” -, que já aparecera no parágrafo 1. A Igreja, caracterizada, superlativamente, no exórdio, pela expressão "o melhor da terra", assume a tarefa de convencer-nos, com o conselho de Cristo, do desapego que merecem as "cousas da terra", lembrando-nos de que somos "terra". Nesse jogo com os significantes, o termo identificador, "cousas da terra", forma um trocadilho com "terra de nosso ser", identificando a natureza corrupta e efêmera das "cousas" com o "ser do ouvinte". Assim fecha o orador o parágrafo 9 do sermão:

Não há dúvida que para concluir o pouco valor das cousas do mundo, bastava considerá-las por comparação à nossa vileza, porém vivemos tão enganados com ele, que não quero deixar esta verdade pendente de uma conseqüência, discorramos brevemente por elas, e veremos a desestima que merecem. ${ }^{16}$

Com essas palavras, não apenas é retomado o termo identificador agora sob a forma das "cousas do mundo" -, mas encaminha-se a argumentação para o desdobramento dele em numerosas particularizações.

Desse modo, abre-se a argumentação, como glosa da primeira metade do conceito predicável - Memento homo quia pulvis es -, numa série de exemplos particulares dos "bens do mundo". Essa série ocupará os parágrafos 10 a 24, num esquema nítido: um exemplo em cada parágrafo. A primeira metade do conceito predicável será retomada, no sermão, no final da primeira parte da argumentação, no parágrafo 26.

\section{Disseminação}

Chamamos "pluralidade de correlação"17 (ou simplesmente "pluralidade") a cada conjunto dos elementos do esquema geral apresentado

16 SÁ, 2006, p. 43.

${ }^{17}$ ALONSO, 2002, v.1, p. 323. 
anteriormente: os primeiros elementos (designados pela letra "A", seguida de um número $-A_{1} \ldots A_{15}$ ) constituem a primeira pluralidade, ou pluralidade básica; os elementos que se seguem a cada um dos anteriores (designados por "A") e que se lhes opõem (designados pela letra "B", seguida de um número $-\mathrm{B}_{1} \ldots \mathrm{B}_{15}$ ) constituem a segunda pluralidade.

Nos parágrafos 10 a 24, em cada um dos itens em que os "bens da terra" se desdobram, o conceito aí apresentado é correlato aos demais de sua pluralidade. Por exemplo, o conceito relativo ao parágrafo 14 , em que aparece o elemento designado por $\mathrm{A}_{5}$, é correlato aos demais da pluralidade básica $-A_{1}, A_{2} \ldots A_{15}-$, uma vez que desenvolve, singularizando-a, a idéia do termo identificador $(\mathrm{AB})$.

Sabemos que um signo pode suscitar uma infinidade de imagens, por meio da expansão de seu campo semântico. Interessa-nos, aqui, destacar a capacidade que têm os signos, componentes da série paralelística designada por $\mathrm{A}_{\mathrm{n}}$, de se conectarem à idéia matriz e motriz $\mathrm{AB}$ ("bens da terra"), geradora das partiçóes e da configuração mais geral do discurso, segundo inumeráveis redes de relações e valências. Essa propriedade dos signos está na base das técnicas de correlação de pluralidades e de disseminaçãorecoleção.

Reexaminemos as pluralidades disseminadas entre os parágrafos 10 e 24. Em cada parágrafo, há uma proposição inicial, ilustrada, veementemente, com exemplos retirados da Bíblia ou da história antiga. Como se fossem pedrinhas de um mosaico, esses parágrafos são fragmentos que compõem uma imagem do mundo (ou seria da corte portuguesa?), na perspectiva de um jesuíta.

Quanto à ordenação, todas as proposições básicas obedecem a uma forte estruturação paradigmática, nos vários níveis: rítmico, sintático, posicional e vocabular. Há, em todas elas, uma espécie de cesura, que destaca os dois membros de uma antítese. O primeiro membro é introduzido pelo advérbio de interrogação "que"; o segundo, pela conjunção adversativa "senão".

A construção bimembre da série proposicional é feita a partir da ambivalência, do jogo entre o parecer e o ser. $\mathrm{O}$ trecho subseqüente à 
primeira parte da proposição, sempre regido pelo advérbio "que", confirma a contínua transformação de um conceito $A_{n}$, em sua imagem invertida, $B_{n}$. A primeira metade da proposição apresenta o que o mundo parece ser; a segunda, o que ele de fato é - segundo o pensamento escolástico-jesuítico.

A divisão da idéia-tema $(\mathrm{AB})$ em partes $\left(\mathrm{A}_{\mathrm{n}}\right)$ é uma operação criadora, porque confere à idéia uma totalidade impensável sem as suas diversas particularizações. O todo só pode existir se divisível em partes discerníveis e organizáveis. Das quinze idéias em que se desdobra a idéia-tema, examinaremos apenas algumas, pois o mecanismo subjacente a toda a série é bastante paralelo.

O primeiro componente particularizado da totalidade abrangida pela idéia-tema aparece no parágrafo 10 e é constituído pelas "grandezas de maior nome", ou seja, concretamente, pelos títulos de nobreza:

$\$ 10$ Que são as grandezas de maior nome $\left[\mathrm{A}_{1}\right]$ senão grandezas de nome $\left[\mathrm{B}_{1}\right]^{18}$

A expressão "grandezas de maior nome", despojada do adjetivo "maior", perde a opulência e revela-se apenas uma "vaidade". Bastou omitir o adjetivo e repetir a construção para inverter o significado inicial e nulificar a majestade do título.

Essa proposição, apresentada no parágrafo 10, é amplificada por reiterações sintáticas, paralelismos e acumulações de toda ordem. $\mathrm{O}$ grande exemplo, no parágrafo, é a figura de Davi, o jovem escolhido por Deus para ser rei dos judeus; mas outro personagem modelar também é citado, São Pedro, o pescador convertido a líder da igreja, por Cristo. Os exemplos (que têm a mesma função) são de homens de origem humilde, nomeados, por Deus, seus representantes na Terra (Rei e Papa, respectivamente), por suas virtudes morais. Davi passa de pastor a rei, donde o pregador explorar o nome de "Davi rei" por oposição ao nome de "Davi pastor"; São Pedro se chamava, antes, Simão, e o pregador associa sua mudança de condição, de pescador a apóstolo e primeiro chefe da igreja, à mudança de nome, de Simão a Pedro.

${ }^{18}$ SÁ, 2006, p. 43. 
Mas o assunto verdadeiramente colocado em discussão no parágrafo é de fundo ético: o orador se posiciona a favor do merecimento pelas açōes (orientadas pelo espírito) e contra o benefício exclusivamente devido à herança sangüínea. Assim se vê como uma pregação servia para enviar uma mensagem moralizante e empenhada, reveladora da intervenção do jesuíta no governo português.

Ao retomar o assunto desse parágrafo, na primeira recolha, que é feita no parágrafo 25 do sermão, Antônio de Sá o vincula ao tipo psicológico, que chamaremos, aqui, de Arquétipo - e será representado pelas letras "AR":

$\$ 25$ que se desvele o soberbo $\left[A R_{1}\right]$ por tais grandezas $\left[A_{1}\right]^{19}$

O sermonista chama de "soberbo" àquele que perde o sono, desvelase; ou seja, empenha-se para obter títulos, "grandezas", só no nome.

A segunda proposição desdobrada da idéia-tema, exposta no parágrafo 11, desempenha papel especial na globalidade do sermão; por isso, citaremos todo o parágrafo:

$\$ 11$ Que é a glória $\left[A_{2}\right]$, senão um deixar de ser $\left[B_{2}\right]$ ? Entre Elias Profeta vivo, e Moisés Profeta morto, apareceu Cristo no Tabor, ${ }^{20}$ porque entre a vida, e a morte, entre o ser, e não-ser, se alterna neste mundo toda a glória. ${ }^{21}$

É esse o menor e mais conciso parágrafo do sermão. Todo ele é estruturado a partir de conjuntos binários, que servem de alicerce à construção textual, favorecendo o reconhecimento, pelo leitor, da lógica construtiva dos parágrafos, das figuras de retórica empregadas e, ainda, da estrutura geral do sermão.

19 SÁ, 2006, p. 59.

${ }^{20} \mathrm{Mt}$ 17, 3 [E eis que lhes apareceram Moisés e Elias conversando com ele]; $M c$ 9, 4 [E lhes apareceram Elias com Moisés, conversando com Jesus.]; Lc 9, 30 [E eis que dois homens conversavam com ele: eram Moisés e Elias que, aparecendo envoltos em glórias, falavam de seu êxodo que se consumaria em Jerusalém]. ${ }^{21}$ SÁ, 2006, p. 45. 
No monte Tabor, aparece Cristo entre Moisés e Elias, todos envoltos em esplendor e beleza. Notar-se-á que Elias fora arrebatado vivo e levado ao Céu, circunstância aproveitada na argumentação. A imagem ilustra a única recompensa que um cristão deve desejar: em vida ou na morte, permanecer perto de Cristo.

O primeiro membro da premissa, "glória", opõe-se a "deixar de ser". A "glória" humana éa negação da essência divina, do "ser" aristotélico-escolástico. A confirmação da proposição inicial do parágrafo funda-se na tensão entre dois pólos: "vida" e "morte", "ser" e "não-ser". Esboça-se, aqui, algo que determinará a oposição básica da peroração do sermão: a oposição entre "cousas da terra" e "cousas do Céu" (essa expressão não ocorre, textualmente, no sermão).

Quando o termo "glória" reaparece na primeira recolha, que ocorre no parágrafo 25, ele ainda designa a "glória terrena"; ou seja, a ilusão que representam a nobreza e os tesouros da terra:

$\$ 25$ que se desvele $[\ldots]$ o desvanecido $\left[\mathrm{AR}_{2}\right]$ por tal glória $\left[\mathrm{A}_{2}\right]^{22}$

E, sendo assim, o termo "glória", é associado, pelo sermonista, à figura arquetípica do "desvanecido" $\left[\mathrm{AR}_{2}\right]$, aquele que se orgulha da "glória" na dimensão humana, que se envaidece com os títulos de nobreza.

Quando o termo "glória" reaparece na segunda recolha, feita no parágrafo 38, ele é o único termo da série que teve sua posição alterada: ele passa à última colocação. A modificação só se justifica por um artifício retórico-expressivo, uma vez que o jogo entre as partes e o todo é sempre medido e proporcionado. Adiante, ao discutir a peroração, tornaremos a essa alteração posicional, que é essencial ao esquema global das correlações.

Passemos, sem transição, ao parágrafo 24, último da série, que parece desempenhar um papel específico - papel esse relacionado à sua posição na série:

${ }^{22}$ SÁ, 2006, p. 59. 
$\$ 24$ Que é finalmente a Corte $\left[\mathrm{A}_{15}\right]$, senão uma roda arrebatada $\left[\mathrm{B}_{15}\right]$, onde atados de seus desejos volteiam os Cortesãos, miseravelmente alegres? Oh roda de Lisboa, que de atados levas? que cuidados de montar arriba, que embaraços de cair abaixo? que pressas ao valer, que desares ao cair? que precipício nos apetites, que quedas na cobiça? que despenhos na inveja, que ruído às esperanças? que porfia aos favores, que queixa aos infortúnios? que tormento aos desenganos? rodam lisonjeiros, voltam ambiciosos, sobe aquele, baixa este, trabalham todos, ri-se o mundo, e anda a roda. ${ }^{23}$

O tema da "Corte", deixado, estrategicamente, para o fechamento da série, completa o círculo que se iniciara com "as grandezas de maior nome" (os títulos de nobreza). Quanto à organização textual, o parágrafo difere bastante dos anteriores. Há, nele, uma acumulação de censuras aos cortesãos, nas quais os temas longamente discutidos nos parágrafos precedentes já são, de certa maneira, recoletados. Mas tal procedimento recoletivo é matizado por uma inespecificidade lexical que não permite ordenar a serialização, ainda que seja assinalado por certas regularidades: as repreensões estão concentradas num trecho, indicadas pelo pronome interrogativo "que". Os sinais de interrogação, concentrados neste parágrafo, indicam o seu caráter de recriminação e, ao mesmo tempo, de espanto do padre, diante dos vícios enumerados. Dito de outro modo: a recoleção ocorre no plano semântico, porque a "Corte", tema do parágrafo, abriga todos os cortesãos cujos vícios foram discriminados nos parágrafos 10 a 23 .

\section{Primeira Recolha}

Tudo indica que a acumulação "pré-recoletiva”, ocorrida no parágrafo 24, é uma espécie de anúncio da primeira recolha - que ocorre no parágrafo 25. Tal expediente - o da repetição com reelaboração - é recurso de organização textual recorrente no Sermão do Dia de Cinza.

${ }^{23}$ SÁ, 2006, p. 57 e 59. 
Para terminar a descrição da série básica estudada no item anterior, cremos haver uma analogia entre o andamento da série e o de certo raciocínio lógico - o silogismo: uma cadeia de premissas arrematada por uma conclusão.

Não há qualquer dificuldade para se identificar o parágrafo 25 como a conclusão das premissas. Inicialmente, há indicações textuais de resumo ou desfecho - "eis aqui o mundo"; em seguida, são retomadas, uma a uma, em procedimento de recolha, as quinze "cousas do mundo" (temas canônicos); e, por fim, essa recolha nomeia o agente que estava subentendido em cada ação.

Quando consideramos todos os temas canônicos discutidos entre os parágrafos 10 e 24, convencemo-nos de que o propósito de toda essa máquina retórica é pôr em movimento uma censura à política da nobreza, pelo viés da moral cristã.

\section{Retorno do Termo Identificador}

Ainda no parágrafo 25, depois de realizada a primeira recolha, reaparece a segunda epígrafe do sermão, com a advertência de Cristo: "Nolite thesaurizare vobis thesauros in terra" - não acumuleis tesouros da terra. Essa advertência já se achava, desde o exórdio do sermão, associada à primeira metade do tema latino: "Memento homo, quia pulvis es" - lembra-te, homem, que és pó. Os "tesouros da terra" são "pó”; eis, novamente retomado, o termo identificador - "os bens da terra":

[...] porque os bens da terra não têm mais de tesouros, do que aquilo, que nós lhe pomos de vontade, porque nós cegamente o queremos, por isso só eles parecem tesouros, não queiramos nós, que logo não sejam tesouros os bens da terra; a não querer nos admoesta Cristo: nolite: e para que a razão obrigue a vontade, insta o conhecimento dos nadas do mundo desde o conhecimento da vileza de nosso ser: Memento homo quia pulvis es. ${ }^{24}$

${ }^{24}$ SÁ, 2006, p. 61. 
Com essas palavras, prepara o sermonista a passagem ou transição para a segunda parte da argumentação, a qual, em relação à primeira parte, adquire feiçōes de argumentação complementar.

\section{Argumentação Complementar}

A segunda parte da argumentação sustenta-se na segunda seção do tema latino, ampliando-o. O parágrafo 27, que dá início ao segundo movimento argumentativo, começa assim:

Et in pulverem reverteris: A segunda razão de nossa conversão a Deus funda a Igreja na fragilidade de nossas vidas, avisa-nos de que havemos de ser mortos, para que saibamos buscar a Deus como mortais; mas é muito para reparar, que se encomenda à memória este aviso: memento $[\ldots]^{25}$

As palavras iniciais são, justamente, as da segunda metade do conceito predicável, as que dizem respeito ao futuro - et in pulverem reverteris.

Há certa simetria entre a primeira e a segunda parte do desenvolvimento. Em ambas, o discurso começa por uma das seções do tema latino. Em ambas as partes, nos momentos iniciais, o discurso focaliza o monarca - o que é atestado com exemplos bíblicos -; mas logo a alocução é estendida à nobreza em geral. Por fim, há uma apreciação parcial referente ao tema latino discutido.

Contudo, apesar da semelhança estrutural, a segunda parte do desenvolvimento tem função relativamente secundária. Antônio de Sá recupera conceitos e imagens já apresentados e os trabalha com recursos expressivos variados, a fim de tornar claros alguns aspectos complementares da primeira parte da pregação.

${ }^{25}$ SÁ, 2006, p. 61 e 63. 


\section{A Última Recolha}

Na peroração, parágrafo 38, Antônio de Sá finaliza a edificação geométrica do sermão. Inicialmente, o pregador recupera os três temas latinos, respeitando as posições e as funções que se lhes foram atribuídas na partição. Em seguida, os elementos que compõem a pluralidade básica são recolhidos, um a um. Contudo, essa recolha apresenta certas particularidades. $\mathrm{Na}$ série básica, o segundo termo da díade é sempre uma perífrase $\left(\mathrm{B}_{\mathrm{n}}\right)$; na peroração, uma palavra simples $\left(\mathrm{B}_{\mathrm{n}}^{\prime}\right)$.

Há outras distinções fundamentais. Na série básica, a conjunção "senão" identifica os membros do conjunto binário - os conceitos $\mathrm{B}_{\mathrm{n}} \mathrm{e} \mathrm{A}_{\mathrm{n}}$ são contrários, mas, de algum modo, se equivalem. Aqui, a preposição "sem" indica ausência - $o$ conceito $B$ ' não participa da idéia de $A_{n}$. Para distinguir essa diferença fundamental entre as díades da série básica e as da peroração, na peroração grafamos a letra que representa o segundo membro do par com aspas simples $\left(\mathrm{B}_{\mathrm{n}}\right)$.

Então, dizemos que $\mathrm{AB}$ ', com aspas simples, designa as "cousas do Céu", por oposição às "cousas da terra" $(\mathrm{AB})$. Os termos $\mathrm{B}_{1}{ }_{1}, \mathrm{~B}_{2}{ }_{2} \ldots \mathrm{B}_{15}$ ' são semelhantes entre si, enquanto espécies antitéticas e ausentes de $A_{1}, A_{2} \ldots A_{15}$, respectivamente. Desse modo, a soma dos conjuntos semelhantes $\mathrm{A}_{1}, \mathrm{~B}^{\prime}$,', $A_{2}, B_{2}^{\prime} \ldots A_{15}, B_{15}^{\prime}$ gera um novo termo identificador - "cousas do Céu" $\left(\mathrm{AB}^{\prime}\right)$-, com que designamos, aqui, os elementos componentes dessa última recolha.

O conceito $A B^{\prime}$, por constituir uma imagem invertida do termo identificador $\mathrm{AB}$, explica a mudança na posiçāo do termo "glória", na peroração. Quando ele ("glória") deixou a segunda posição para ocupar a última, o artifício reduz todas os pares a uma díade totalizante ( $A B$ '), intensificando a tensão entre os termos antitéticos "cousas da terra" e "cousas do Céu".

$\mathrm{Na}$ expressão "glória sem fim" ( $\mathrm{A}_{2}, \mathrm{~B}$ '), a locução adjetiva "sem fim" equivale ao adjetivo "eterna". Podemos reconhecer, facilmente, na nova expressão ("glória eterna"), um sentido preciso - "o Céu" ou sua representação "com a Santíssima Trindade, os anjos e os bem-aventurados". ${ }^{26}$ Assim, o par

${ }^{26}$ HOUAISS, 2001, verbete: glória. 
$\mathrm{A}_{2}, \mathrm{~B}_{2}$ não só preserva sua função na correlação, mas também aglomera todos os conjuntos da peroração. Em resumo, o conjunto binário $\mathrm{A}_{2}, \mathrm{~B}_{2}{ }_{2}$ corresponde a AB' ("cousas do Céu”).

Para terminar este estudo estrutural funcional dos paradigmas textuais, toda a globalidade do sermão pode ser representada por uma fórmula:

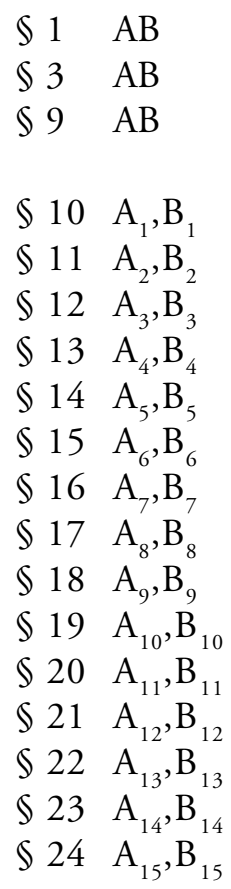

$\$ 25 \mathrm{AB} ; \mathrm{AB} ; \mathrm{AR}_{1}, \mathrm{~A}_{1} ; \mathrm{AR}_{2}, \mathrm{~A}_{2} ; \mathrm{AR}_{3}, \mathrm{~A}_{3} ; \mathrm{AR}_{4}, \mathrm{~A}_{4} ; \mathrm{AR}_{5}, \mathrm{~A}_{5} ; \mathrm{AR}_{6}, \mathrm{~A}_{6} ;$ $\mathrm{AR}_{7}, \mathrm{~A}_{7} ; \mathrm{AR}_{8}, \mathrm{~A}_{8} ; \mathrm{AR}_{9}, \mathrm{~A}_{9} ; \mathrm{AR}_{10}, \mathrm{~A}_{10} ; \mathrm{AR}_{11}, \mathrm{~A}_{11} ; \mathrm{AR}_{12}, \mathrm{~A}_{12} ; \mathrm{AR}_{13}, \mathrm{~A}_{13} ;$ $\mathrm{AR}, \mathrm{A}_{14} ; \mathrm{AR}, \mathrm{A}_{15} ; \mathrm{AR}, \mathrm{AB}$

$\S 38 \mathrm{AB}^{\prime}: \mathrm{A}_{1}, \mathrm{~B}_{1}^{\prime} ; \mathrm{A}_{3}, \mathrm{~B}_{3}{ }_{3} ; \mathrm{A}_{4}, \mathrm{~B}_{4} ; \mathrm{A}_{5}, \mathrm{~B}_{5} ; \mathrm{A}_{6}, \mathrm{~B}_{6}{ }_{6} ; \mathrm{A}_{7}, \mathrm{~B}_{7}{ }_{7} ; \mathrm{A}_{8}, \mathrm{~B}_{8} ; \mathrm{A}_{9}, \mathrm{~B}_{9} ;$ $\mathrm{A}_{10}, \mathrm{~B}_{10}{ }_{10} ; \mathrm{A}_{11}, \mathrm{~B}_{11}{ }_{12} ; \mathrm{A}_{12}, \mathrm{~B}_{12} ; \mathrm{A}_{13}, \mathrm{~B}_{13} ; \mathrm{A}_{14} \mathrm{~B}_{14} ; \mathrm{A}_{15}, \mathrm{~B}_{15} ; \mathrm{A}_{2}, \mathrm{~B}_{2}{ }_{2}\left[\mathrm{AB}^{\prime}\right]$

Eis como se nos apresenta um sermão correlativo e disseminativorecoletivo. 


\section{Referências bibliográficas}

ALONSO, D. Táticas dos conjuntos semelhantes na expressão literária. In: LIMA, Luiz Costa Lima. Teoria da literatura em suas fontes. Rio de Janeiro: Francisco Alves, 2002. v. I. p. 317-340.

ARISTÓTELES. Arte poética e arte retórica. São Paulo: Difusão Européia do Livro, 1959.

BARTHES, Roland. Sade, Fourier, Loyola. São Paulo: Martins Fontes, 2005. BÍBLIA de Jerusalém. São Paulo: Paulus, 2003.

CANDIDO, Antonio. O estudo analítico do poema. 4. ed. São Paulo: Associação Editorial Humanitas, 2004.

HOUAISS, Antônio et al. Dicionário eletrônico Houaiss da língua portuguesa. Rio de Janeiro: Objetiva, 2001.

LAPA, Rodrigues. Estilistica da Lingua Portuguesa. 7. ed. Rio de Janeiro: Livraria Acadêmica, 1973.

LEITE, Serafim. História da Companhia de Jesus no Brasil. Rio de Janeiro: Instituto Nacional do Livro, 1950. 10v.

LIMA, Luiz Costa Lima. Teoria da literatura em suas fontes. Rio de Janeiro: Francisco Alves, 2002. v. I. p.297-318.

MENDES, Margarida Vieira. A oratória Barroca de Vieira. Lisboa: Editorial Caminho, 1989.

SÁ, Antônio de. Sermão do Dia de Cinza. In: SANTOS, Gilson José. Sermão do Dia de Cinza, do padre Antônio de Sá: edição e estudo crítico. 2006. Dissertação (Mestrado em Estudos Literários - Literatura Brasileira) Programa de Pós-graduação em Estudos Literários, Faculdade de Letras, Universidade Federal de Minas Gerais, Belo Horizonte, 2006. p. 31.

SANTOS, Gilson José. Sermão do Dia de Cinza, do padre Antônio de Sá: edição e estudo crítico. 2006. Dissertação (Mestrado em Estudos Literários - Literatura Brasileira) - Programa de Pós-graduação em Estudos Literários, Faculdade de Letras, Universidade Federal de Minas Gerais, Belo Horizonte, 2006. 
SARAIVA, Antônio José. O discurso engenhoso: estudos sobre Vieira e outros autores barrocos. São Paulo: Perspectiva, 1980. (Coleção Debates).

TRINGALI, Dante. Introdução à retórica: a retórica como crítica literária. São Paulo: Duas Cidades, 1988. (Estante do Estudante)

\section{Resumo}

Este estudo descreve a estrutura correlativa do Sermão do Dia de Cinza, de Antônio de Sá (1620-1678). Neste texto - pregado na Capela Real, em Lisboa, na Quaresma - o orador procura persuadir o monarca português e sua corte ao temor de Deus e à piedade. A questão essencial que norteia a argumentação é a mortalidade do homem, sobretudo do homem nobre.

\section{Abstract}

This study describes the correlative structure of the Sermão do Dia de Cinza (Sermon of Ash Wednesday), by Antônio de Sá (1620?-1678). In this text - preached in the Real Chapel, in Lisbon, during the Lent - the orator intends to persuade the Portuguese monarch and his court to practice fear of God and piety. The essential element that supports the argumentation process in this sermon is the awareness of human mortality, above all of the noblemen. 